\title{
EL ACCESO A LA JUSTICIA DEL NIÑO, NIÑA Y ADOLESCENTE ${ }^{1}$
}

\author{
ACCESS TO JUSTICE FOR CHILDREN AND ADOLESCENTS
}

\author{
Domingo Bello Janeiro ${ }^{2}$ \\ Universidad de La Coruña \\ La Coruña, España \\ https:/ / orcid.org/0000-0002-9696-7069 \\ domingo.bello@udc.es
}

\section{Resumen}

Los niños son un grupo vulnerable con especiales dificultades para ejercitar con plenitud ante el sistema de justicia los derechos reconocidos por el ordenamiento jurídico que hay que dar adecuada protección para lo cual lo primero es que los niños sean más conscientes de sus derechos a ser oídos y escuchados, especialmente en casos de violencia de género, con especial cuidado en su acceso a la justicia en relación con la prohibición legal de la guarda y custodia compartida de hijos menores así como en la suspensión de la medida de custodia compartida acordada en sentencia, siendo necesario prestar atención psicológica tras procedimiento judicial seguido contra víctimas de violencia de género, así como prevenir la violencia de género digital entre los jóvenes y dotar de una normativa de protección integral a la infancia especialmente frente a la lacra de la violencia.

Palabras clave: acceso a la justicia, colectivo vulnerable, violencia de género, custodia compartida, atención psicológica, violencia digital

\section{Abstract}

Children are vulnerable group with special difficulties protection for which the frst thing is that children are more aware of their rights to be heard and heard, especially in cases of gender-based violence, with special care in their access to justice in relation to the legal prohibition of joint custody and custody of minor children, as well as in the suspension of the joint custody measure agreed in the judgment, being It is necessary to provide psychological care after legal proceedings against victims of gender violence, as well as to prevent digital gender violence among young people and provide comprehensive protection regulations for children, especially against the scourge of violence.

Keywords: access to justice, vulnerable collective, gender violence, shared custody, psychological care, digital violence

1 Ponencia presentada en el Pre Congreso Mundial por los Derechos de la Infancia y la Adolescencia, realizado los días 26 y 27 de agosto de 2021, vía plataforma virtual; organizado por el Master en Derecho de Familia e Infancia de la Universidad de Barcelona, la Asociación para la Defensa de los Derechos de la Infancia y la Adolescencia (ADDIA) y el Instituto de la Familia de la Facultad de Derecho de la Universidad Femenina del Sagrado CorazónUNIFE.

2 Abogado, catedrático de Derecho Civil de la Universidad La Coruña, España. 


\section{INTRODUCCIÓN. NORMATIVA INTERNACIONAL Y ESPAÑOLA}

Comienzo mi colaboración con el especial agradecimiento, -al margen de formalismos protocolarios-, por la amable invitación a participar en esta revista, felicitando por dicha iniciativa, y centrando mi trabajo en el estudio de la normativa internacional y española sobre el derecho del niño (como colectivo vulnerable) a acceder a la justicia, y a ser oído y escuchado en los casos de violencia de género; centrándome principalmente en el acceso a la justicia de los niños en relación con la prohibición legal de la guarda y custodia compartida de hijos menores, así como en la suspensión de la medida de custodia compartida acordada en sentencia para luego continuar con el análisis de la atención psicológica tras el procedimiento judicial seguido contra víctimas de violencia de género; la prevención de la violencia de género digital entre los jóvenes y la normativa española sobre protección de la infancia y adolescencia, para culminar con la sucinta exposición del novedoso Proyecto de Ley Orgánica de Protección Integral a la Infancia y la Adolescencia frente a la Violencia, que trata en España de dar respuesta a la obligación de protección de las personas menores de edad donde tiene especial interés e incidencia digna de adecuada protección el derecho que ocupa nuestra atención seguidamente.

Los niños, niñas y adolescentes, en el contexto del principio fundamental de acceso a la justicia, han sido definidos como un grupo vulnerable hasta el punto de que las Reglas de Brasilia, sobre acceso a la justicia de las personas en condición de vulnerabilidad, adoptadas en la XIV Cumbre Judicial Iberoamericana de 2008, que tiene como finalidad asegurar el acceso a la justicia de éstas, en su Sección $2^{\circ}, \mathrm{N}^{\circ} 1$ señala literalmente que "Se consideran en condición de vulnerabilidad aquellas personas que, por razón de su edad, género, estado físico o mental, o por circunstancias sociales, económicas, étnicas y/o culturales, encuentran especiales dificultades para ejercitar con plenitud ante el sistema de justicia los derechos reconocidos por el ordenamiento jurídico. Señalan además que podrán constituir causas de vulnerabilidad, entre otras, las siguientes: la edad, la discapacidad, la pertenencia a comunidades indígenas o a minorías, la victimización, la migración y el desplazamiento interno, la pobreza, el género y la privación de libertad", siendo relevante al respecto resaltar en Perú que el Poder Judicial se adhirió a las 100 Reglas de Brasilia mediante las Resoluciones Administrativas №266-2010-CE-PJ y N¹982020-CE-PJ, la cual sirvió de fuente para el Plan Nacional de Acceso a la Justicia de Personas en Condición de Vulnerabilidad 2016-2021, aprobado a través de la Resolución Administrativo N090-2016-CE-PJ. 
El derecho del niño, niña y adolescente a acceder a la justicia y a ser oído y escuchado es uno de los principios generales de la Convención sobre los Derechos del Niño adoptada por la Asamblea General de las Naciones Unidas el 20 de noviembre de 1989 siendo en España su instrumento de ratificación del 30 de noviembre de 1990. (BOE 31 de diciembre de 1990) junto con el derecho a la no discriminación, el derecho a la vida y desarrollo y el interés superior del niño, garantizando el artículo 12 de la Convención a todo niño que esté en condiciones de formar un juicio propio a expresar su opinión libremente, tras lo que se otorga al niño el derecho a ser escuchado en todo procedimiento judicial o administrativo que le afecte.

En concreto, dicho artículo 12 de la Convención sobre los Derechos del Niño, dispone literalmente que:

1. Los Estados Partes garantizarán al niño, que esté en condiciones de formarse un juicio propio, el derecho de expresar su opinión libremente en todos los asuntos que afectan al niño, teniéndose debidamente en cuenta las opiniones del niño, en función de la edad y madurez del niño. 2. Con tal fin, se dará en particular al niño oportunidad de ser escuchado en todo procedimiento judicial o administrativo que afecte al niño, ya sea directamente o por medio de un representante o de un órgano apropiado, en consonancia con las normas de procedimiento de la ley nacional. (Convención sobre los Derechos del Niño, artículo 12).

En la Observación General número doce del Comité de los Derechos del Niño en 2009 se concretó que los Estados partes tienen la obligación de adoptar las medidas necesarias con el fin de respetar este derecho de los niños y tomar en cuenta la opinión que emita sin presión y con respeto a la decisión del niño de ejercer o no su derecho, por lo que "deberían escuchar atentamente las opiniones de los niños siempre que su perspectiva pueda aumentar la calidad de las soluciones", con la obligación de tener "debidamente en cuenta las opiniones del niño, en función de la edad y madurez del niño".

Al respecto, la sentencia del Tribunal Europeo de Derechos Humanos, Sección $3^{a}$, de 11 de octubre de 2016 considera que:

en lo que respecta particularmente al trámite de audiencia de las niñas por parte de un Tribunal, el TEDH ha estimado que sería ir demasiado lejos decir que los Tribunales internos están siempre obligados a oír a un niño en audiencia cuando está en juego el derecho de visita 
de un padre que no ejerce la guarda. En efecto, esto depende de las circunstancias particulares de cada caso y teniendo debida cuenta de la edad y de la madurez del niño afectado. (Tribunal Europeo de Derechos Humanos, 11 de octubre de 2016, Sección 3ª)

Por lo que se refiere a la normativa española, el artículo 92.6 del Código Civil estatuye la audiencia de los menores por el juez, cuando tengan suficiente juicio y el juez lo estime necesario, añadiendo, por su parte, el art. 770.1.4 ${ }^{\mathrm{a}}$ de la Ley de Enjuiciamiento Civil (LEC) que «se les oirá, si tuvieren suficiente juicio $\mathrm{y}$, en todo caso, si fueren mayores de 12 años», mientras que el art. 777.5 de la LEC, con una redacción similar a la del Código Civil, concede amplias facultades al juez para oír o no al menor.

Es básico en España al respecto el artículo 9 de la Ley de Protección del Menor, respecto al derecho a ser oído, señalándose en el párrafo primero que el menor tiene derecho a ser oído, tanto en el ámbito familiar como en cualquier procedimiento administrativo o judicial en que esté directamente implicado y que conduzca a una decisión que afecte a su esfera personal, familiar o social, con la precisión de que en los procedimientos judiciales, las comparecencias del menor se realizarán de forma adecuada a su situación y al desarrollo evolutivo de éste, cuidando de preservar su intimidad.

A continuación en el apartado 2 de dicho precepto de la Ley española del Menor se dice que se garantizará que el menor pueda ejercitar este derecho por sí mismo o a través de la persona que designe para que le represente, cuando tenga suficiente juicio, si bien, no obstante, cuando ello no sea posible o no convenga al interés del menor, podrá conocerse su opinión por medio de sus representantes legales, siempre que no sean parte interesada ni tengan intereses contrapuestos a los del menor, o a través de otras personas que por su profesión o relación de especial confianza con él puedan transmitirla objetivamente.

De modo especial, en el apartado 3 del citado artículo 9 de la citada Ley española de Protección del Menor se consagra la necesidad de oír a los menores sobre la guarda y custodia, disponiéndose en concreto que "cuando el menor solicite ser oído directamente o por medio de persona que le represente, la denegación de la audiencia será motivada y comunicada al Ministerio Fiscal y a aquéllos «.

En el derecho español, según hemos adelantado, en caso de procedimiento contencioso de divorcio, y si se estima necesario, los hijos menores, si son capaces de discernimiento, deben ser oídos por el Juez y, en 
todo caso, los menores con edades de 12 y más años, debiendo de motivarse del denegación del trámite de audiencia, en cualquier caso, cuando el menor solicita ser oído, sobre lo cual ha recaído nutrida doctrina jurisprudencial del Tribunal Supremo y del propio Tribunal Constitucional.

Así, sobre la necesidad de oír a los menores sobre la guarda y custodia, la Sentencia del Tribunal Supremo de 20 de octubre de 2014, concluye que «La aparente contradicción entre el Código Civil y la Ley de Enjuiciamiento Civil viene a ser aclarada por la Ley del Menor y por el Convenio sobre Derechos del Niño, en el sentido de que cuando la edad y madurez del menor hagan presumir que tiene suficiente juicio y, en todo caso, los mayores de 12 años, habrán de ser oídos en los procedimientos judiciales en los que se resuelva sobre su guarda y custodia, sin que la parte pueda renunciar a la proposición de dicha prueba, debiendo acordarla, en su caso, el juez de oficio.

En similar dirección la sentencia del Tribunal Constitucional de 6 de junio de 2005, señala que para que el juez o tribunal pueda decidir no practicar la audición, en aras al interés del menor, será preciso que lo resuelva de forma motivada, tras lo cual concluye que "en función de lo expuesto procede acordar la nulidad de oficio de la sentencia recurrida, retrotrayendo las actuaciones al momento anterior a dictar sentencia para que antes de resolver sobre la guarda y custodia de los menores, se oiga a los mismos de forma adecuada a su situación y a su desarrollo evolutivo, cuidando de preservar su intimidad.»

\section{EL ACCESO A LA JUSTICIA DEL NIÑO EN CASOS DE VIOLENCIA DE GÉNERO.}

Especial atención tiene el ejercicio de ese fundamental derecho en casos de violencia de género en que un porcentaje altísimo de los menores expuestos a dicha lacra presentó algún trastorno psicológico al menos leve, siendo también muy frecuente que buena parte de dichos episodios de violencia se han llevado a cabo tras la separación de los progenitores en el momento en que el padre ejerce el régimen de visitas concertado o acordado judicialmente, por lo que resulta necesario extremar la cautela en todos los sentidos en el propio procedimiento civil y siempre primando el interés del menor y su fundamental derecho a ser oído y escuchado singularmente en estos casos extremos de violencia de género.

En España la Ley Orgánica 8/2015, de 22 de julio, de modificación del sistema de protección a la infancia y a la adolescencia, califica de "especialmente atroz" la violencia que sufren quienes viven y crecen en un entorno donde está 
presente la violencia de género que afecta a los menores de muchas formas, condicionando su bienestar y desarrollo, causándole serios problemas de salud, convirtiéndolos en instrumento para ejercer dominio y violencia sobre la mujer $\mathrm{y}$, en fin, favoreciendo la transmisión intergeneracional de estas conductas violentas sobre la mujer por parte de sus parejas o ex parejas.

En este texto legal precisamente se define el interés superior del menor como un derecho sustantivo en el sentido de que el menor tiene derecho a que, cuando se adopte una medida que le concierna, sus mejores intereses hayan sido evaluados y, en el caso de que haya otros intereses en presencia, se hayan ponderado a la hora de llegar a una solución y, además, es un principio general de carácter interpretativo de modo que si una disposición jurídica puede ser interpretada en más de una forma se debe optar por la interpretación que mejor responda a los intereses del menor así como, en último lugar, dicho principio es igualmente una norma de procedimiento para asegurar el respeto completo y efectivo de todos los derechos del menor, así como su desarrollo integral.

Resulta, pues, de especial relevancia el derecho que nos ocupa del menor a ser oído y escuchado en estos casos de violencia de género en que, en España, hasta el momento de entrada en vigor de la Ley Orgánica 1/2004, de 28 de diciembre, de Medidas de Protección Integral contra la Violencia de Género, el legislador había dado respuesta al problema de la violencia tradicionalmente denominada doméstica y, ahora, de género, únicamente a través de instrumentos propios del Derecho penal.

Sin embargo, frente a esta respuesta expresa en el Derecho penal, en otros sectores del Ordenamiento en los que, sin duda, resultaba conveniente la previsión de medidas complementarias que pudiesen adoptarse como necesario complemento de las penales o con independencia de la posible respuesta penal por no resultar esta adecuada o por tratarse de acontecimientos que, por la razón que fuese, careciesen de relevancia penal o la víctima no considere oportuno que lleguen a conocimiento de un órgano jurisdiccional de esta naturaleza, no se había adoptado previsión alguna ni substantiva ni procesal hasta que la Ley Orgánica 1/2004 ofrece un marco jurídico en el que se contemplan expresamente medidas de protección de las víctimas de la violencia de género de naturaleza estrictamente civil.

Uno de los fines esenciales de la Ley Orgánica 1/2004 está constituido por asegurar una protección integral, desde las instancias jurisdiccionales, a las víctimas de violencia de género. A estos efectos, combina mecanismos penales de tutela, con medidas de naturaleza civil y también del orden social o laboral, en el que se 
establecen algunos ejemplos de la denominada discriminación positiva a favor de la mujer que haya sido víctima de violencia de género.

En efecto, estamos ante una norma con una clara vocación de globalidad, tal y como se afirma en su propia Exposición de Motivos, pues con ella se pretende atender las recomendaciones de los organismos internacionales en el sentido de proporcionar una respuesta global a la violencia que se ejerce sobre las mujeres.

Ha de tenerse en cuenta la modificación del Código Civil operada por la Ley 13/2005 de 1 de julio, admitiendo el matrimonio entre personas del mismo sexo con los mismos requisitos y efectos que el matrimonio entre heterosexuales por lo que es legalmente posible que dos personas del mismo sexo puedan contraer matrimonio y por tanto, separarse o divorciarse por lo que hay que distinguir entre supuestos de violencia de género en el sentido del art. 1 de la LO 1/2004 y casos de violencia en el seno de un matrimonio contraído entre un hombre y una mujer, con o sin hijos- o de violencia doméstica -categoría, ésta, más amplia que engloba los supuestos de violencia en un matrimonio formado por dos hombres o dos mujeres, violencia de los padres sobre los menores, violencia de los menores sobre los padres y violencia entre hermanos de modo que, en conclusión, la referencia en esta Ley al concepto de violencia doméstica y no a la violencia de género se justifica precisamente por dicha modificación del Código Civil operada por la Ley $13 / 2005$.

Puesto que los descendientes menores son considerados también sujetos pasivos de las infracciones penales para cuyo conocimiento es competente el Juzgado de Violencia sobre la Mujer, siempre que además se haya producido un acto de violencia contra ésta [art. 87 ter.1.a) LOPJ], las medidas civiles expuestas pueden ser necesarias para proteger y evitar perjuicios a dichos menores cuando sean destinatarios directos o indirectos de esos actos de violencia, siendo el factor relevante a estos efectos el del interés del menor, a cuya protección integral hay que atender de manera preferente a la hora de acordar tales medidas, por encima de los legítimos intereses de sus progenitores incluida la mujer víctima de la violencia de género en los términos de la Ley 8/2015, de 22 de julio, de modificación del sistema de protección a la infancia y a la adolescencia (ex arts. 39 de la CE y 2 de la Ley Orgánica de Protección Jurídica del Menor y de los arts. 92, párrafo 21, 154 y 158 , entre otros, del CC, en relación con la Convención de Derechos del Niño de Naciones Unidas, de 20 de noviembre de 1989, ratificada por España el 30 de noviembre de 1990), conforme a la cual hay que velar porque el niño no sea separado de sus padres, excepto cuando tal separación sea necesaria para el interés superior del menor, 
como es el caso de ser objeto de maltrato por parte de sus padres (art. 9.1 ), debiendo respetarse el derecho del niño que esté separado de uno o de ambos progenitores a mantener relaciones personales y contacto directo con ellos de modo regular, salvo que sea contrario el superior interés del menor ( art. 3.2 ).

En cuanto al régimen de visitas, la mera alegación o constancia de una situación de violencia de género no debe determinar, automáticamente, la suspensión de dicho régimen al progenitor inculpado, sino que habrán de analizarse todas las circunstancias concurrentes y en particular el peligro generado para el menor, procurando la fijación de un régimen singularizado y adaptado a las necesidades del caso concreto en interés del menor, que puede ir desde la suspensión temporal de las visitas o comunicaciones hasta su ejercicio a través de mecanismos de mediación, como la presencia de terceras personas o el uso de los llamados puntos de encuentro.

Para lograr con eficacia la finalidad de estas medidas, parece oportuno resaltar que no basta con la creación de órganos judiciales especializados, como es el Juzgado de Violencia sobre la Mujer, si no se cuenta en sede judicial con equipos periciales en materia psicosocial que informen adecuadamente al Juez sobre la incidencia de la violencia enjuiciada en las medidas protectoras que se pudieran acordar.

\section{LA PROHIBICIÓN LEGAL DE LA GUARDA Y CUSTODIA COMPARTIDA DE LOS HIJOS MENORES.}

Pocos días después de la entrada en vigor de la LO 1/2004 en sus aspectos más relevantes y de cuyo análisis, desde la perspectiva del Derecho civil, me he ocupado hasta el momento, en España la Ley 15/2005, de 8 de julio, por la que se modificaron el Código Civil (CC) y la Ley de Enjuiciamiento Civil (LECiv) en materia de separación y divorcio ha venido a completar el panorama que desde la antedicha perspectiva pueden adoptarse en los supuestos en que concurra una situación de violencia de género.

En efecto, frente a la posibilidad de que en los procesos matrimoniales de separación, divorcio y nulidad matrimoniales, bien los progenitores de común acuerdo en el convenio regulador (art. 92.5 del CC), bien en virtud de acuerdo posterior adoptado en el seno del procedimiento matrimonial y previo informe del Ministerio Fiscal y audiencia de los menores cuando tengan suficiente juicio (arts. 92.5 y 6 del CC), de que se acuerde la guarda y custodia compartida por los dos progenitores de sus hijos menores de edad, el legislador ha establecido, para dos casos concretos, la prohibición legal de adoptar la guarda y custodia 
compartida de los hijos sometidos a patria potestad, cuales son los constituidos por la existencia de indicios fundados de existencia de un supuesto de violencia doméstica y por aquel en que uno de los progenitores esté incurso en un proceso penal iniciado por atentar contra la vida, la integridad física, la libertad, la integridad moral o la libertad e indemnidad sexual del otro cónyuge o de los hijos que convivan con ambos (art. 92.7 del CC), siendo en todo caso en ambos casos fundamental el acceso del menor a la justicia para que puedan garantizarse plenamente sus derechos fundamentales.

La referencia que el art. 92.7 del CC realiza al concepto de violencia doméstica y no a la violencia de género, pese a que a primera vista pudiera parecer una incorrección técnica, tiene su justificación, pues, merced a la modificación del Código Civil operada por la Ley 13/2005 de 1 de julio, admitiendo el matrimonio entre personas del mismo sexo con los mismos requisitos y efectos que el matrimonio entre heterosexuales, es legalmente posible que dos personas del mismo sexo puedan contraer matrimonio y por tanto, separarse o divorciarse y también, adoptar hijos en común. Por lo que dependiendo del sexo de los cónyuges podremos estar antes supuestos de violencia de género en el sentido del art. 1 de la LO 1/2004 de casos de violencia en el seno de un matrimonio contraído entre un hombre y una mujer, con o sin hijos- o de violencia doméstica -categoría, ésta, más amplia que engloba los supuestos de violencia en un matrimonio formado por dos hombres o dos mujeres, violencia de los padres sobre los menores, violencia de los menores sobre los padres y violencia entre hermanos, por lo que ahora nos interesa-.

La redacción del artículo 92 del código civil dada por la Ley 15/2005, de 8 de julio dispone en sus apartados $5^{\circ}, 6^{\circ}$ y $7^{\circ}$ que: "Se acordará el ejercicio compartido de la guarda y custodia de los hijos cuando así lo soliciten los padres en la propuesta de convenio regulador o cuando ambos lleguen a este acuerdo en el transcurso del procedimiento. El Juez, al acordar la guarda conjunta y tras fundamentar su resolución, adoptará las cautelas procedentes para el eficaz cumplimiento del régimen de guarda establecido, procurando no separar a los hermanos.

En todo caso, antes de acordar el régimen de guarda y custodia, el Juez deberá recabar un informe del Ministerio Fiscal, y oír a los menores que tengan suficiente juicio cuando se estime necesario de oficio o a petición del Fiscal, partes o miembros del Equipo Técnico Judicial, o del propio menor, valorar las alegaciones de las partes vertidas en la comparecencia y la prueba practicada en ella, y la relación que los padres mantengan entre sí y con sus hijos para determinar su idoneidad con el régimen de guarda". 
En la actualidad los tribunales vienen instaurando un sistema que ofrezca más ventajas a los menores. La doctrina jurisprudencial ha evolucionado desde una guarda y custodia mayoritariamente materna a una configuración actual de custodia compartida atendiendo a la doctrina jurisprudencial del Tribunal Supremo y de la reciente regulación normativa de las comunidades autónomas en materia de corresponsabilidad parental.

La reciente regulación legal entiende que ambos progenitores son aptos y tienen la misma capacidad y aptitud para asumir la guarda y custodia de los hijos, siempre con la excepción del apartado $7^{\circ}$ del artículo 92 del código civil para los supuestos de violencia de género.

El Tribunal Supremo considera que el régimen más deseable y beneficioso para el menor es el de custodia compartida. El criterio que la Sala de lo Civil del Tribunal Supremo viene manteniendo se realiza siempre bajo la prevalencia del respeto del interés superior de los menores, optando por el sistema que en el caso concreto se adapte mejor al menor y a su interés, no al de sus progenitores. En este sentido cabe indicar que el Tribunal Supremo ha dictado diferentes sentencias, entre ellas, y a modo de ejemplo, en Sentencia de 29 de marzo de 2016, de la Sala Primera de lo civil 194/2016, en recurso 1159/2015, el Tribunal Supremo ha optado por el régimen de custodia compartida y entiende que apartarse de la misma pone en evidente riesgo la seguridad jurídica en un sistema necesitado de una solución homogénea por parte de los Tribunales a los asuntos similares.

En Sentencia de la Sala Primera de lo Civil, 116/2017, de 22 de febrero el Tribunal Supremo realiza una interpretación del régimen de custodia compartida, entendiendo que éste es el más frecuente para aplicar la guarda y custodia de menores ante la separación o divorcio de los progenitores.

De la lectura de la sentencia reseñada se puede extraer que "los criterios que la sala viene manteniendo al respecto, siempre bajo la prevalencia del respeto del interés superior de los menores, parten de la necesidad de optar por el sistema que en el caso concreto se adapte mejor al menor y a su interés, no al interés de sus progenitores, habiéndose reiterado que la redacción del artículo 92 CC no permite concluir que se trate de una medida excepcional, sino que, al contrario, habrá de considerarse normal e incluso deseable, teniéndose en cuenta la práctica anterior de los progenitores en sus relaciones con el menor y sus aptitudes personales; los deseos manifestados por los menores; el número de hijos; el cumplimiento por parte de los progenitores de sus deberes en relación con los mismos y el respeto mutuo en sus relaciones personales; el resultado de los informes obrantes en autos y finalmente cualquier otro elemento que 
permita valorar con mayor precisión cuál es el interés de los menores en el caso concreto (SSTS 10 y 11 de marzo de 2010, 7 de julio de 2011, 29 abril de 2013, 25 de abril, 22 y 30 de octubre, y 18 noviembre 2014, 16 de febrero y 17 de julio de 2015, y 30 de mayo de 2016, entre otras)".

En cuanto al primer inciso del art. 92.4 del CC, en tanto que prevé que la custodia compartida se excluye de forma imperativa -no procederá- cuando cualquiera de los progenitores esté incurso en un proceso penal iniciado, por atentar contra la vida, la integridad física, la libertad, la integridad moral o la libertad e indemnidad sexual del otro cónyuge o de los hijos que convivan con ambos, puede plantear en la práctica judicial, numerosos problemas. En efecto, si pensamos en una situación de normal convivencia familiar el esposo comete actos de violencia definidos en el art. 1.3 de la LO 1/2004 de 28 de diciembre de Medidas de Protección Integral contra la Violencia de Género, sobre la mujer o sobre la mujer y los hijos.

En ambos casos, se tratará de actos de violencia de género, competencia de los Juzgados de Violencia sobre la Mujer, según lo dispuesto en el art. 44.1 de esta Ley. La esposa, víctima de la agresión, presenta la correspondiente denuncia ante la policía o querella ante el Juzgado de Violencia sobre la Mujer o el Juzgado de Guardia, iniciándose las correspondientes actuaciones penales por delito o falta (el único supuesto que queda son las injurias o vejaciones de carácter leve, ya que las coacciones y amenazas leves son consideradas delitos cuando se trata de la esposa del autor del hecho o mujer que haya estado ligada a él por análoga relación de afectividad aún sin convivencia). Incoado el correspondiente proceso penal por un acto de violencia de género, la esposa inicia también, la tramitación de un procedimiento matrimonial con la presentación de la demanda de separación o divorcio. En el seno de este procedimiento civil se excluye expresamente por el legislador la posibilidad de adoptar la medida de custodia compartida, independientemente de los acuerdos a los que lleguen las partes del proceso.

Fácil es colegir que en estos supuestos, la guarda y custodia de los hijos menores se le va a atribuir, en la sentencia que ponga fin al procedimiento matrimonial, en exclusiva, a la esposa y esto con independencia por un lado, de la suerte que corra el procedimiento penal, pues el juez puede acordar el archivo de la causa, por estimar que el hecho no es constitutivo de infracción penal o que no aparece debidamente justificada su perpetración (arts. 637, 641 y 779 de la LECrim) o puede dictar auto de sobreseimiento incluso de forma provisional y por otro, de la solución a la que se llegue en el proceso penal; por ejemplo, se que dicte una sentencia absolutoria. En el supuesto de que el procedimiento matrimonial haya seguido una tramitación más rápida, la custodia no pudo 
ser adoptada en su seno, por impedírselo la ley expresamente, por lo que, al esposo absuelto del delito o falta que le había sido imputado por la esposa, no le queda otra alternativa, si quiere la custodia de los hijos, que iniciar el correspondiente procedimiento civil de modificación de medidas definitivas, de acuerdo con lo que dispone el art. 775 de la LEC.

Un segundo supuesto que se puede plantear es el que sigue: los esposos deciden disolver el matrimonio, bien de mutuo acuerdo, bien forma contenciosa presentando la correspondiente demanda de divorcio. Estando en curso este procedimiento civil, la esposa presenta una denuncia imputando al esposo la comisión de un acto de violencia doméstica. El art. 92.7 del CC precisa que no procederá la guarda conjunta cuando cualquiera de los padres esté incurso en un proceso penal iniciado. La pregunta que ha de hacerse en este caso es la atinente a ¿cuándo se entiende iniciado el proceso penal? A los efectos de tenerlo en cuenta para la adopción de una medida tan importante cual es la de decidir con cuál de los progenitores van a vivir los hijos, a sabiendas que en este tema viven entremezcladas cuestiones no sólo afectivas sino también económicas, la decisión de determinar cuál de los progenitores ejercerá la custodia sobre los hijos, lleva de la mano otras medidas, sumamente importantes, como son la atribución del domicilio familiar, la pensión de alimentos, etc., hay que entender que la mera presentación de una denuncia o querella, si no va seguida de su admisión a trámite, no supone la iniciación del proceso penal, deben de haberse incoado diligencias previas o juicio de faltas o haberse dictado auto de admisión de la querella.

Más controvertido ha resultado todavía, desde el mismo momento en que se inicio la tramitación legislativa de la reforma del CC en esta materia la causa que determina la imposibilidad de adoptar en el seno de un procedimiento matrimonial la guarda y custodia compartida de los hijos menores que se contempla en el inciso segundo del art. 92.7 del CC: Tampoco procederá cuando el Juez advierta, de las alegaciones de las partes y las pruebas practicadas, la existencia de indicios fundados de violencia doméstica.

Hay que entender que cuando de los escritos de demanda o de contestación, de las manifestaciones de las partes vertidas en el procedimiento matrimonial -en la comparecencia o en el acto de la vista-, de la conducta de los cónyuges, de las manifestaciones de terceros que declaren en calidad de testigos por haber observado hechos de interés para apreciar la existencia de un acto de violencia doméstica, de la prueba documental o pericial-consistente en la presentación de informes médicos o policiales que hayan sido fruto de una labor de investigación-, en una valoración conjunta de todas estas 
pruebas, el Juez que conozca del proceso matrimonial considera que ponen de manifiesto la existencia de indicios fundados de violencia doméstica, tampoco procederá la custodia compartida. En todo caso, no se trata de una interdicción que proceda sin realizar un análisis adecuado del material probatorio puesto a disposición del Juzgador y que ha acreditar, al menos de manera indiciaria y fundada la presencia de un acto de violencia doméstica, sin necesidad de que el delito o la falta había se haya probado. Un supuesto que encaja en este precepto es el de que se haya dictado una orden de protección en el marco de la Ley 27/2003, de 31 de julio, reguladora de la Orden de Protección de las Víctimas de Violencia Doméstica, a raíz de los episodios violentos perpetrados por uno de los cónyuges o convivientes, en su caso.

Con ocasión de la adopción de la orden de protección pueden adoptarse también medidas de naturaleza civil, de carácter cautelar y provisional, previas a la demanda iniciadora del juicio de familia, siempre que no hubieran sido previamente acordadas por un órgano del orden jurisdiccional civil y sin perjuicio de las medidas previstas en el art. 158 del CC. Estas medidas pueden consistir en la atribución del uso y disfrute de la vivienda familiar a la víctima del acto de violencia doméstica, determinar el régimen de custodia, visitas, comunicación y estancia con los hijos, el régimen de prestación de alimentos, etc. (art. 544 ter.7 último párrafo LECrim). Cuando concurran los presupuestos que la ley señala para la adopción de la orden de protección, el juez podrá incorporar la medida de atribuirle la custodia de los hijos al progenitor sujeto pasivo de la violencia de doméstica. Presentada la correspondiente demanda que da lugar a la iniciación del procedimiento de familia, esta medida puede ser ratificada, modificada o dejada sin efecto por el juez que conozca, posteriormente del proceso civil. En la mayoría de los casos, esta medida de atribución en exclusiva de la guarda y custodia a uno de los padres, ya provisional en el seno del proceso de separación y divorcio, puede estar vigente a lo largo de toda la tramitación del procedimiento civil, hasta que sea sustituida por la correspondiente medida definitiva, recogida en la sentencia de primera instancia, sino es recurrida y si lo es, puede ser modificada o confirmada por la de alzada.

\section{LA SUSPENSIÓN DE LA MEDIDA DE CUSTODIA COMPARTIDA ACORDADA EN SENTENCIA}

En el supuesto de que se haya tramitado un procedimiento matrimonial al margen de toda relación con actos de violencia de género y de violencia doméstica y en la sentencia que puso fin se haya acordado la custodia compartida de los hijos con fundamento en las previsiones del art. 92.5 del CC o antes 
de su entrada en vigor, de conformidad con la doctrina jurisprudencial que excepcionalmente admitía esta posibilidad-, si en un momento determinado el marido, por ejemplo, protagoniza un acto de violencia de género sobre la todavía esposa, en el supuesto de que no hayan disuelto el vínculo matrimonial en virtud de divorcio o de nulidad matrimonial- o sobre la que ha dejado de serlo, el Juez puede, mediante Auto, suspender para el inculpado por violencia de género el ejercicio de la guarda y custodia respecto de los hijos comunes menores concedida en el procedimiento civil anteriormente tramitado v.gr., el de separación matrimonial en el primero de los casos enunciado-, de acuerdo con lo dispuesto en los arts. 61 y ss de la LO 1/2004, no es necesario que el menor, respecto del que se suspenda la guarda y custodia, sea la víctima del acto de violencia de género y ello por cuanto la prohibición se acuerda respecto del inculpado por la violencia de género.

Esta medida cautelar que resulta compatible con cualesquiera de las medidas cautelares y de aseguramiento que se puedan adoptar en los procedimientos civiles y penales que se incoen (ex art. 158 del CC) puede estar vigente, como medida de seguridad, tras la sentencia definitiva y durante su ejecución e, incluso, durante la tramitación de los eventuales recursos que correspondan, debiendo contemplarse no como una sanción al maltratador, sino como una medida que debe adoptarse preordenada a la protección del superior interés del menor. Por ello, debe de ser proporcional al hecho cometido respetando los principios de contradicción, audiencia y defensa (ex art. 68 de la LO 1/2004).

Existen diferentes sentencias del Tribunal Supremo que estiman improcedente la aplicación de la custodia compartida. A modo de ejemplo, en Sentencia de 4 de febrero de 2016 el Tribunal Supremo ha manifestado que "Es doctrina de esta Sala que [SSTS 29 de abril de 2013, ; 16 de febrero, y 21 de octubre 2015, la custodia compartida conlleva como premisa la necesidad de que entre los padres exista una relación de mutuo respeto en sus relaciones personales que permita la adopción de actitudes y conductas que beneficien al menor, que no perturben su desarrollo emocional y que pese a la ruptura afectiva de los progenitores se mantenga un marco familiar de referencia que sustente un crecimiento armónico de su personalidad. Y es que una cosa es la lógica conflictividad que puede existir entre los progenitores como consecuencia de la ruptura, y otra distinta que ese marco de relaciones se vea tachado por una injustificable condena por un delito de violencia de género que aparta al padre del entorno familiar y de la comunicación con la madre, lo que va a imposibilitar el ejercicio compartido de la función parental adecuado al interés de los hijos. El art. 2 de la Ley 8/2015, de 22 de julio, de modificación del sistema de protección a la infancia y a la adolescencia, exige que la vida y desarrollo del menor se desarrolle en un entorno «libre de violencia» y que «en caso de que 
no puedan respetarse todos los intereses legítimos concurrentes, deberá primar el interés superior del menor sobre cualquier otro interés legítimo que pudiera concurrir»; criterios que aun expresados en una ley posterior a la demanda, incorpora los que esta Sala ha tenido reiteradamente en cuenta a la hora de integrar el interés del menor. Corolario lógico es lo dispuesto en el artículo 92.7 del Código Civil (...).

\section{ATENCIÓN PSICOLÓGICA TRAS PROCEDIMIENTO JUDICIAL A MENORES VÍCTIMAS DE VIOLENCIA DE GÉNERO}

En España se produjo una rara unanimidad en el Congreso de los Diputados para convalidar el RDL sobre violencia de género pues todas las formaciones han apoyado también su tramitación como proyecto de Ley de modo que el Congreso de los Diputados ha convalidado el Real Decreto-Ley 9/2018, de 3 de agosto, de medidas urgentes para el desarrollo del Pacto de Estado contra la Violencia de Género, que modifica la Ley de Bases del Régimen Local, la Ley de Medidas de Protección Integral contra la Violencia de Género y el Código Civil.

La iniciativa ha salido adelante por 335 votos a favor y 2 abstenciones, y se tramitó como proyecto de ley por el procedimiento de urgencia considerándose en el mismo a los Ayuntamientos como 'espacios seguros' para la mujer, se amplían los mecanismos de acreditación y, por lo que a nosotros más nos interesa ahora, se lleva a cabo la modificación del Código Civil en materia de patria potestad

El decreto incluye una modificación en el artículo 156 del Código Civil para desvincular la intervención psicológica con menores expuestos a violencia de género del ejercicio de la patria potestad, a fin de que en estos casos no sea necesaria la autorización de los dos progenitores para acceder a la asistencia psicológica.

En concreto la reforma que afecta al artículo 156 del Código Civil tiene como objetivo que la atención y asistencia psicológica quede fuera del catálogo de actos que requieren una decisión común en el ejercicio de la patria potestad, cuando cualquiera de los progenitores esté incurso en un proceso penal iniciado por atentar contra la vida, la integridad física, la libertad, la integridad moral o la libertad e indemnidad sexual del otro progenitor o de los hijos e hijas de ambos.

En España, la situación de los menores, víctimas de violencia, son casi de un $60 \%$ y la corta edad del $93,7 \%$ de ellos, no les permite identificar como tal 
la situación en la que viven, lo que hace necesario poner en marcha la ayuda en ese tramo de minoría de edad y por eso se contempla la modificación del Código Civil.

Esta norma plantea, además, la necesidad de adoptar las modificaciones legales oportunas para que la Administración local pueda llevar a cabo actuaciones en la promoción de la igualdad entre hombres y mujeres, así como contra la violencia de género, ya que se trata de la administración más cercana a la ciudadanía y, por ende, a las víctimas para lo cual, estas cuestiones pasarán a ser competencia propia de los municipios en el artículo 25.2 de la Ley 7/1985, de 2 de abril, Reguladora de las Bases del Régimen Local.

Se presume que una víctima de violencia machista acudirá antes a una casa consistorial que a una comisaría, de ahí que este decreto busque este cambio de competencias y permita a los ayuntamientos contratar personal especializado para la detección de casos para intentar convertir el ayuntamiento en un espacio seguro para la mujer y, por lo que a nosotros interesa en este texto, para los menores.

Para fortalecer la tutela judicial y el acceso a la justicia, y a los recursos de asistencia de las víctimas de violencia de género y a los menores, el RDL modifica los artículos 20 y 23.

En este último, se amplían los mecanismos de acreditación de las situaciones de violencia de género, de modo que se podrá realizar mediante una sentencia condenatoria por un delito de violencia de género, una orden de protección o "cualquier otra resolución judicial" que acuerde una medida cautelar a favor de la víctima, o bien por el informe del Ministerio Fiscal que indique la existencia de indicios de que la demandante es víctima de violencia de género.

También podrán acreditarse las situaciones de violencia de género mediante informe de los servicios sociales, de los servicios especializados, o de los servicios de acogida destinados a víctimas de violencia de género de la Administración Pública competente; o "por cualquier otro título", siempre que ello esté previsto en las disposiciones normativas de carácter sectorial que regulen el acceso a cada uno de los derechos y recursos.

Por lo que respecta al artículo 20 contiene tres tipos de medidas "destinadas a mejorar la participación de la víctima en el proceso penal". Por un lado, se reforma su apartado 4 y se añade un apartado 5 para reforzar la asistencia jurídica de las víctimas. 
Y se añade un nuevo apartado 6 para implementar una medida del Pacto de Estado referente a la habilitación legal del Letrado de la víctima a fin de que pueda ostentar su representación procesal hasta la personación de la víctima en el procedimiento, si bien esto debe armonizarse con la tercera medida consistente en la adición de un nuevo apartado 7 con el objeto de permitir a la víctima personarse como acusación particular en cualquier fase del procedimiento.

Finalmente se modifica el artículo 27, referente a las ayudas sociales, a fin de permitir la compatibilidad con cualquiera de las prestaciones previstas en la Ley 35/1995, de 11 de diciembre, de Ayudas y Asistencia a las Víctimas de Delitos Violentos y contra la Libertad Sexual, así como con cualquier otra ayuda económica de carácter autonómico o local concedida por la situación de violencia de género.

En resumen, de lo anteriormente expuesto, el 3 de agosto de 2018, el Consejo de Ministros aprobó el Real Decreto-ley (publicado en BOE el 4 de agosto de 2018) de medidas urgentes para el desarrollo del Pacto de Estado contra la Violencia de Género, que modifica la Ley de Bases del Régimen Local, la Ley de Medidas de Protección Integral contra la Violencia de Género y el Código Civil y que afecta a los procedimientos y a las implicaciones de la labor de los psicólogos en este ámbito.

En primer lugar, entre las nuevas medidas que contempla la normativa se incluye una modificación en el artículo 156 de Código Civil para que la atención y asistencia psicológica a los menores quede fuera del catálogo de actos que requieren una decisión común en el ejercicio de la patria potestad, cuando cualquiera de los progenitores esté incurso en un proceso penal por atentar contra la vida, la integridad física, la libertad, la integridad moral o la libertad e indemnidad sexual del otro progenitor o de los hijos e hijas de ambos. De este modo, a partir de la aprobación de este Real Decreto, los menores expuestos a violencia de género no requerirán el consentimiento del progenitor condenado o acusado para recibir atención psicológica, debiendo tan sólo de ser informado previamente. Asimismo, si los menores tienen más de 16 años será necesario también contar con el consentimiento de ellos para poder prestar dicha atención psicológica.

Específicamente, el nuevo párrafo segundo incorporado en el artículo 156 del Código Civil queda redactado de la siguiente manera:

Dictada una sentencia condenatoria y mientras no se extinga la responsabilidad penal o iniciado un procedimiento penal contra uno de 
los progenitores por atentar contra la vida, la integridad física, la libertad, la integridad moral o la libertad e indemnidad sexual de los hijos o hijas comunes menores de edad, o por atentar contra el otro progenitor, bastará el consentimiento de éste para la atención y asistencia psicológica de los hijos e hijas menores de edad, debiendo el primero ser informado previamente. Si la asistencia hubiera de prestarse a los hijos e hijas mayores de dieciséis años se precisará en todo caso el consentimiento expreso de éstos. (Código Civil español, art. 156)

A su vez, el texto incorpora otras medidas para ampliar los mecanismos de acreditación de las situaciones de violencia de género, fortalecer las competencias de los Ayuntamientos en materia de violencia de género y mejorar la tutela judicial y la participación de la víctima en el proceso penal (mediante la designación urgente de abogados y procuradores de oficio que aseguren la inmediata presencia para la defensa y representación de las víctimas y la posibilidad de que la víctima se persone como acusación particular en cualquier fase del procedimiento).

Estos cambios también suponen una serie de implicaciones para la labor de los psicólogos en este campo porque, por un lado, los informes de los psicólogos de los servicios sociales, de los servicios especializados o de los servicios de acogida destinados a víctimas de violencia de género de la Administración Pública competente, podrían empezar a considerarse válidos para acreditar la condición de sufrir violencia de género y tener acceso a los derechos que establece la legislación vigente. No obstante, este procedimiento está pendiente de la regulación que establecerá reglamentariamente el Gobierno y las Comunidades Autónomas, en el marco de la Conferencia Sectorial de Igualdad.

A este respecto, el nuevo artículo 23 de la Ley Orgánica 1/2004, de 28 de diciembre, de Medidas de Protección integral contra la Violencia de Género, queda redactado de la siguiente manera:

Artículo 23. Acreditación de las situaciones de violencia de género. Las situaciones de violencia de género que dan lugar al reconocimiento de los derechos regulados en este capítulo se acreditarán mediante una sentencia condenatoria por un delito de violencia de género, una orden de protección o cualquier otra resolución judicial que acuerde una medida cautelar a favor de la víctima, o bien por el informe del Ministerio Fiscal que indique la existencia de indicios de que la demandante es víctima de violencia de género. También podrán acreditarse las situaciones de violencia de género mediante informe de los servicios sociales, de los 
serviciosespecializados, odelosservicios deacogida destinadosa víctimas de violencia de género de la Administración Pública competente; o por cualquier otro título, siempre que ello esté previsto en las disposiciones normativas de carácter sectorial que regulen el acceso a cada uno de los derechos y recursos. El Gobierno y las Comunidades Autónomas, en el marco de la Conferencia Sectorial de Igualdad, diseñarán, de común acuerdo, los procedimientos básicos que permitan poner en marcha los sistemas de acreditación de las situaciones de violencia de género. (Ley Orgánica 172004, 28 de diciembre 2004, articulo 23)

Por otro lado, los psicólogos que trabajen en el marco de las administraciones locales pasan a tener pleno respaldo legal para dar asistencia a las víctimas de violencia de género, a diferencia de lo que venía ocurriendo, al contar las administraciones locales a partir de ahora con las competencias relacionadas con «Actuaciones en la promoción de la igualdad entre hombres y mujeres así como contra la violencia de género", tal y como queda recogido en el apartado 2 del artículo 25 de la Ley 7/1985, de 2 de abril, Reguladora de las Bases del Régimen Local.

\section{PREVENCIÓN DE LA VIOLENCIA DE GÉNERO DIGITAL ENTRE LOS JÓVENES}

El Pleno del Congreso de los Diputados, en su sesión de 12 de junio de 2018, ha acordado aprobar con modificaciones una Proposición no de Ley presentada en abril de este mismo año por el Grupo Parlamentario Popular, relativa a la prevención de la violencia de género digital entre la juventud.

En su Exposición de Motivos, el Grupo Popular lamentaba que, pese a las distintas iniciativas que se han emprendido con el fin de concienciar y sensibilizar a la población adolescente sobre la violencia de género, la última estadística anual del Observatorio contra la Violencia Doméstica y de Género del Consejo General del Poder Judicial "refleja un incremento de los casos de violencia de género entre parejas adolescentes", debido, según la presidenta del Observatorio, a un inicio cada vez más temprano de las relaciones, así como al uso de las nuevas tecnologías y las redes sociales "que son un importante campo de cultivo para ejercer una violencia de control sobre las adolescentes", al permitir al maltratador controlar con mucha más facilidad a su pareja.

Exponiendo datos tan alarmantes como los que recoge el Centro Reina Sofía sobre Adolescencia y Juventud a través de sus diferentes encuestas -en los cuales se refleja cómo el $27 \%$ de los jóvenes españoles considera que la violencia de género es una conducta normal en el seno de la pareja, y más del $80 \%$ de los 
adolescentes afirma conocer algún caso de malos tratos en parejas de su edad-, el PP hacía hincapié en su propuesta en fomentar la prevención de la violencia de género digital, "que se ceba en mujeres cada vez más jóvenes", impulsando que valores como la igualdad y el respeto sean los ejes de cualquier relación.

Tras un intenso debate, durante el cual distintos grupos parlamentarios presentaron diversas enmiendas, la propuesta se votó en los términos de una enmienda transaccional presentada por el Grupo Parlamentario Popular en el Congreso, el Grupo Confederal de Unidos Podemos-En Comú Podem-En Marea, el Grupo Ciudadanos y el Grupo Mixto, quedando aprobada finalmente con 333 votos favorables, uno negativo y 5 abstenciones, tal como sigue:

El Congreso de los Diputados insta al Gobierno a:

- Seguir impulsando, en el marco del Plan Director para la Mejora de la Convivencia y la Seguridad en Centros Educativos, y en el marco de lo aprobado en el Pacto de Estado contra la Violencia de Género, la concienciación y la formación para la igualdad tanto de los adolescentes como de sus padres, madres y docentes.

- Continuar realizando campañas específicas en medios digitales, utilizando el contexto vital de los propios adolescentes, para informarles del valor de la privacidad y su relación con la ciberseguridad, respetando el marco de lo aprobado en el Pacto de Estado contra la Violencia de Género.

- Reforzar la difusión de recursos de apoyo, anónimos y online, que sirvan para formular consultas o denuncias.

- Promover sistemas que evalúen las prácticas de autorregulación, desde el punto de vista de la igualdad, con el fin de eliminar contenidos nocivos, en el marco de lo aprobado en el Pacto de Estado contra la Violencia de Género.

- Establecer mecanismos de protección e intensificar campañas en los ámbitos educativos para prevenir el "grooming" o engatusamiento por parte de adultos para perpetrar delitos contra los menores (tráfico de pornografía infantil, abusos, chantajes, etc.) amparándose en la red.

- Desarrollar una línea de trabajo, en el marco del Plan Estratégico de Convivencia Escolar 2017, de prevención y detección de la violencia de género en los centros educativos. 
- Convocar el Observatorio de Convivencia Escolar y dotarlo de medios y mecanismos para poder hacer efectivas las funciones que le corresponden.

- Promover en los centros educativos el desarrollo de planes de convivencia escolar que ayuden a prevenir la violencia de género en centros educativos, que incluyan formación, el respeto y la igualdad entre personas.

- Reforzar y ampliar en materia de educación, los valores igualitarios y la educación afectivo-sexual obligatoria en todos los niveles educativos, fomentando que los mismos se aborden de forma integral (aspectos fisiológicos y afectivo-emocionales).

- Incluir, en todas las etapas educativas, la prevención de la violencia de género, del machismo y de las conductas violentas, la educación emocional y sexual y la igualdad, incluyendo además en los currículos escolares, los valores de la diversidad y la tolerancia. Garantizar su inclusión a través de la Inspección Educativa.

- Establecer mecanismos que garanticen la aplicación de protocolos de actuación y de mediación en los casos de violencia de género en todos los centros educativos, tanto públicos como privados o privados concertados.

- Suprimir de los libros de texto y del material educativo en general aquellos contenidos y elementos que perpetúen un modelo machista."

\section{EL SISTEMA DE PROTECCION DE LA INFANCIA Y ADOLESCENCIA.}

En España, la Ley Orgánica 8/2015, de 22 de julio, de modificación del sistema de protección de la infancia y adolescencia señala que, transcurridos 20 años desde la publicación de la Ley Orgánica 1/1996, de 15 de enero, de Protección Jurídica del Menor, esta norma tiene por objeto complementar la Ley de modificación del sistema de protección a la infancia y la adolescencia, introduciendo los cambios jurídicos-procesales y sustantivos necesarios en aquellos ámbitos reservados a la Ley Orgánica, al incidir en los derechos fundamentales y libertades públicas establecidos en los artículos 14, 15, 16, 17.1, 18.2 y 24 de la Constitución.

Para ello se lleva a a cabo una profunda reforma de la LO 1/1996 y otra veintena de normas más relacionadas con la materia, entre ellas la LEC, la 
LOPJ, la LO sobre derechos y libertades de los extranjeros en España y la LO de Protección contra la Violencia de Género, comenzando por concretar el concepto jurídico indeterminado "interés superior del menor" incorporando, tanto la jurisprudencia del Tribunal Supremo, como los criterios de la Observación general n. 14 , de 29 de mayo de 2013, del Comité de Naciones Unidas de Derechos del Niño, sobre el derecho del niño a que su interés superior sea una consideración primordial.

Según hemos ya adelantado, se da al concepto un contenido triple: como derecho sustantivo, como principio general de carácter interpretativo y como norma de procedimiento y así se parte de que, sin perjuicio de los establecidos en la legislación específica aplicable, así como de aquellos otros que puedan estimarse adecuados atendiendo a las circunstancias concretas del supuesto "A efectos de la interpretación y aplicación en cada caso del interés superior del menor, se tendrán en cuenta los siguientes criterios generales: la satisfacción de las necesidades básicas del menor, la consideración de sus deseos, sentimientos y opiniones, o la conveniencia de que su vida y desarrollo tenga lugar en un entorno familiar adecuado y libre de violencia".

Estos criterios habrán de ponderarse en función de determinados elementos generales, como la edad y madurez del menor, la necesidad de garantizar su igualdad y no discriminación por su especial vulnerabilidad, o la necesidad de estabilidad de las soluciones que se adopten

Como tercer elemento que ha de intervenir en la defensa del interés superior del menor, se hace referencia a la necesidad de respetar las garantías procesales, en particular: los derechos del menor a ser informado, oído y escuchado; la intervención en el proceso de profesionales cualificados o expertos o la adopción de una decisión que incluya en su motivación los criterios utilizados.

La norma establece que, en caso de que no puedan respetarse todos los intereses legítimos concurrentes, deberá primar el interés superior del menor sobre cualquier otro interés legítimo.

Se desarrolla, de forma más detallada, el derecho fundamental del menor a ser oído y escuchado de acuerdo con las recomendaciones y criterios de los Convenios Internacionales ratificados por España y en tal sentido se establece el derecho del menor ser oído y escuchado sin discriminación alguna por edad, discapacidad o cualquier otra circunstancia, tanto en el ámbito familiar como en cualquier procedimiento administrativo, judicial o de mediación en que esté afectado. 
En España en esta norma se sustituye el término juicio por el de madurez, considerando, en todo caso, que los menores tienen suficiente madurez a los doce años cumplidos, se establece que en los procedimientos judiciales o administrativos, las comparecencias o audiencias del menor tendrán carácter preferente y se detallan las especiales necesidades que el menor tiene para poder ejercer adecuadamente este derecho y los correspondientes medios para satisfacerlas.

Por último, se incorpora la posibilidad de que los menores planteen sus quejas ante la figura del Defensor del Pueblo o instituciones autonómicas homólogas y se refuerza la tutela judicial efectiva de los menores introduciendo la posibilidad de solicitar asistencia legal y nombramiento de un defensor judicial.

Por otra parte, se regulan los ingresos, actuaciones e intervenciones en centros de protección específicos de menores con problemas de conducta destinados al acogimiento residencial de menores que estén en situación de guarda o tutela de la Entidad Pública, diagnosticados con problemas especiales de conducta y que tienen en cuenta las especiales características, complejidad, condiciones y necesidades de estos menores, previéndose como último recurso, la utilización de medidas de seguridad y de restricción de libertades o derechos fundamentales.

Por ello, es necesaria una normativa en la que se determinen los límites de la intervención, regulándose, entre otras cuestiones, las medidas de seguridad como la contención, el aislamiento o los registros personales y materiales, la administración de medicamentos, el régimen de visitas, los permisos de salida o sus comunicaciones.

El ingreso en estos centros requiere autorización judicial, que puede ser solicitada por la Entidad Pública que ostente la tutela o guarda del menor, o por el Ministerio Fiscal, precisándose que las medidas de seguridad aplicadas han de ser el último recuro, y tendrán siempre carácter educativo.

Se regulan dos nuevos procedimientos ágiles y sumarios en la LECiv., comenzando, en primer lugar, por el procedimiento para la obtención de la autorización judicial del ingreso de un menor en un centro de protección específico de menores con problemas de conducta. Se exige que se realice previa autorización del Juez de Primera Instancia, tras lo que se detalla el procedimiento para conocer de las solicitudes para entrar en un domicilio en ejecución de las resoluciones administrativas de protección de menores. Se atribuye la competencia para la autorización de entrada en domicilio al 
Juzgado de Primera Instancia, eliminando eta competencia de los Juzgados de lo Contencioso-administrativo. Se prevé la posibilidad de acordar la entrada de forma inmediata sin oir al titular u ocupante del domicilio.

Se amplía de treinta a noventa días el período de reflexión que se da a las víctimas de trata de seres humanos, para que decidan si desean cooperar con las autoridades en la investigación del delito, y, en su caso, en el procedimiento penal y se reconoce expresamente como víctimas de violencia de género a los menores y se hace hincapié en la obligación de los jueces de pronunciarse sobre las mediadas civiles que afectan a los menores que dependen de la mujer sobre la que se ejerce violencia.

\section{LA PROTECCIÓN INTEGRAL A LA INFANCIA Y LA ADOLESCENCIA FRENTEA LA VIOLENCIA}

En la última parte de mi trabajo me centraré en la decisión adoptada por el Consejo de Ministros del gobierno de España el 10 de junio de 2020 cuando aprobó remitir a las Cortes Generales el Proyecto de Ley Orgánica de Protección Integral a la Infancia y la Adolescencia frente a la Violencia, que trata de dar respuesta a la obligación de protección de las personas menores de edad establecida en la Convención sobre los Derechos del Niño, (adoptada por la Asamblea General de las Naciones Unidas el 20 de noviembre de 1989 y ratificada por España en 1990), en el artículo 3 del Tratado de Lisboa y en el artículo 39 de la Constitución Española.

Según informó el Gobierno español, este Proyecto ha sido desarrollado en un amplio proceso de consultas y aportaciones con el resto de administraciones, las organizaciones especializadas en infancia y el conjunto de la sociedad civil.

El Comité de Derechos del Niño, con ocasión del examen de la situación de los derechos de la infancia en España en 2018, reiteró a nuestro país la necesaria aprobación de una ley integral sobre la violencia contra los niños y niñas, análoga a la aprobada contra la violencia de género.

Esta Ley responde a esta necesidad, e incluye medidas en muchos ámbitos (prevención, actuación en el nivel educativo, apoyo familiar, servicios sociales, sanidad, regulación de la publicidad, redes sociales, justicia...), teniendo en cuenta varias de las Observaciones Generales $(12,13$ y 14) realizadas por el Comité de Derechos del Niño de Naciones Unidas y los estándares internacionales desarrollados por el Consejo de Europa en sus distintos convenios. 
Además, la Ley está orientada al cumplimiento de los objetivos de la Agenda 2030, en particular el Objetivo 16 ("Promover sociedades, justas, pacíficas e inclusivas") y la meta 16.2 ("Poner fin al maltrato, la explotación, la trata y todas las formas de violencia y tortura contra los niños"), exponiendo a continuación brevemente sus principales contenidos por su novedad y porque en gran medida tienen especial incidencia en el derecho del niño y niña a ser oído y escuchado.

En concreto, esta nueva norma persigue establecer un nuevo paradigma de prevención y protección común en todo el territorio del Estado español frente a la vulneración de derechos que significa la violencia sobre la infancia y la adolescencia.

Este paradigma se caracteriza por una aproximación integral con la que dar respuesta a un problema que tiene una naturaleza multidimensional, así como la priorización de la prevención como vía para evitar la violencia contra las personas menores de edad, reforzando también las capacidades de los propios niños, niñas y adolescentes para la detección precoz y la adecuada reacción ante situaciones de violencia, tras lo que se destaca el establecimiento de medidas de protección orientadas a eludir la victimización secundaria y, por último, la superación de la fragmentación del modelo actual, mediante la colaboración con las Comunidades Autónomas.

Las principales novedades que introduce este Proyecto de Ley Orgánica son que se garantiza a los niños, niñas y adolescentes víctimas de violencia los derechos a la información, el asesoramiento y el apoyo, a una atención integral (incluida la atención terapéutica) y, lo que a nosotros más nos interesa ahora, a personarse en los procedimientos judiciales que se sigan, a la par que se promueve y garantiza la formación especializada, inicial y continua en materia de derechos fundamentales de la infancia y la adolescencia de los y las profesionales que tengan un contacto habitual con personas menores de edad por las Administraciones Públicas y se generaliza el deber de comunicar cualquier situación de violencia sobre niños, niñas o adolescentes a la autoridad competente aun cuando no sea constitutiva de delito. Este deber de comunicación se configura de una forma más exigente para aquellos colectivos profesionales que tengan un contacto habitual con personas menores de edad.

Igualmente se destaca que las Administraciones Públicas deberán establecer mecanismos adecuados de comunicación, accesibles y seguros, por lo que se fomenta la comunicación de situaciones de violencia sobre los niños, niñas y adolescentes por otros menores y se establece la Conferencia 
Sectorial de infancia y adolescencia, como órgano de cooperación entre las Administraciones Públicas para garantizar la necesaria cooperación entre las mismas en la aplicación de esta ley y a fin de analizar su puesta en marcha, sus repercusiones jurídicas y económicas y evaluar su impacto se crea una Comisión de Seguimiento.

En el Proyecto se lleva a cabo la elaboración de una Estrategia para la erradicación de la violencia sobre la infancia y la adolescencia a nivel nacional en colaboración con las comunidades autónomas, las Ciudades de Ceuta y Melilla, y las entidades locales, a la par que se refuerzan las actuaciones de sensibilización, detección precoz y prevención con planes y programas públicos dirigidos a la erradicación de la violencia sobre la infancia y la adolescencia dotados presupuestariamente y que prioricen a los colectivos más vulnerables.

Asimismo, se dice que se proporcionará el apoyo público necesario para prevenir desde la primera infancia factores de riesgo, reforzar factores protectores, así como apoyar la labor educativa de las familias, y, en tal dirección, se promoverá el buen trato, la parentalidad positiva, la adquisición de competencias emocionales, de negociación y resolución de conflictos en base a la situación y necesidades de los progenitores, o en su caso, de las personas tutoras o guardadoras o acogedoras.

De forma coordinada con la reforma de la Ley de Educación, se crea la figura del coordinador o coordinadora de bienestar y protección en los centros educativos y se definen sus funciones básicas para asegurar el adecuado funcionamiento de los protocolos de actuación frente a indicios de acoso escolar, ciberacoso, acoso sexual, violencia de género y cualquier otra forma de violencia y se prevé que los centros de Educación Superior promoverán la formación, docencia e investigación en derechos de la infancia y adolescencia en general.

Se garantiza el acceso universal de los niños, niñas y adolescentes, que se encuentren en situaciones de violencia, a los servicios sanitarios de tratamiento y rehabilitación y, según se especifica en este proyectado texto legal que estamos exponiendo, se desarrollará un protocolo común de actuación sanitaria para facilitar la promoción del buen trato, la identificación de factores de riesgo y la prevención y detección precoz de la violencia sobre niños, niñas y adolescentes en este contexto.

Por otra parte, se atribuye la condición de agentes de la autoridad a los funcionarios que desarrollan su actividad profesional en los servicios 
sociales a la par que se optimiza la información estadística sobre los casos de violencia sobre la infancia y la adolescencia en el Registro Unificado de Servicios Sociales sobre Violencia contra la Infancia con la procedente de los servicios sociales de atención primaria.

Atención psicológica tras procedimiento judicial a menores víctimas de violencia de género

Se regulan las actuaciones públicas dirigidas a garantizar el uso seguro y responsable de Internet por parte de los niños, niñas y adolescentes, familias, personal educador y profesionales que trabajen con personas menores de edad y se crea la figura del delegado de protección en las entidades que realizan actividades deportivas o de ocio con personas menores de edad para informar y apoyar a los niños, niñas y adolescentes para el cumplimiento de los protocolos de actuación frente a la violencia en este ámbito.

Se establece que las Fuerzas y Cuerpos de Seguridad, a nivel estatal, autonómico y local cuenten con unidades especializadas en la sensibilización, prevención de situaciones de violencia sobre personas menores de edad a la par que se reduce la práctica de diligencias con intervención de personas menores de edad a aquellas que sean estrictamente necesarias, regulándose el canal específico de denuncia ante la Agencia Española de Protección de Datos para garantizar una adecuada protección del derecho fundamental a la protección de datos personales y la rápida retirada de Internet los contenidos que atenten gravemente contra el mismo.

Por lo que se refiere a los centros de protección deberán contar con protocolos de actuación para la prevención, detección precoz e intervención frente a las situaciones de violencia comprendidas en esta ley, destacándose los protocolos que contemplen específicamente actuaciones respecto a la trata de seres humanos, el abuso y la explotación sexual de personas menores de edad sujetas a medidas protectoras y que residan en dichos centros.

Se prevé un aumento de la dotación presupuestaria en el ámbito de la Administración de Justicia y la Administración de los Servicios Sociales para luchar contra la victimización secundaria y cumplir las nuevas obligaciones encomendadas por la ley respectivamente y se perfecciona la regulación relativa a la certificación negativa del Registro Central de delincuentes sexuales de no haber cometido delitos contra la libertad o indemnidad sexuales o de trata de seres humanos con fines de explotación sexual para desarrollar actividades que supongan contacto habitual con personas menores de edad. 
Se obliga a denunciar al cónyuge y a los familiares cercanos de la persona que haya cometido un hecho delictivo cuando se trate de un delito grave cometido contra una persona menor de edad y se pauta como obligatoria la práctica de la prueba preconstituida por el órgano instructor, cuando la víctima sea una persona menor de catorce años o con discapacidad necesitada de especial protección a fin de evitar que tenga que declarar reiteradamente, a lo largo del procedimiento penal, sobre los hechos objeto del procedimiento.

Se atribuye la facultad de decidir el lugar de residencia de los hijos menoresdeedad a ambos progenitores. Por tanto, se requiere el consentimiento de ambos o autorización judicial para el traslado de la persona menor de edad, con independencia de la medida que se haya adoptado en relación a su guarda o custodia, salvo suspensión o privación de la potestad o atribución exclusiva de dicha facultad a uno de los progenitores.

Se regula la necesidad de formación especializada en las carreras judicial y fiscal, exigida por toda la normativa internacional, en materia de derechos fundamentales de la infancia y la adolescencia, tras lo cual se prohíbe la publicidad que por sus características pueda provocar en personas menores de edad la adopción de conductas violentas sobre sí mismas o sobre terceros, así como los que integren una serie de estereotipos de carácter sexista, racista, estético o de carácter homofóbico o transfóbico.

Se da una nueva regulación a los delitos de odio, incorporando la edad como causa de discriminación, tanto sobre los niños, niñas y adolescentes, como sobre las personas de edad avanzada e incluyendo la aporofobia y la exclusión social dentro de estos tipos penales y se endurecen las condiciones para el acceso al tercer grado de clasificación penitenciaria, a la libertad condicional y a los permisos penitenciarios por parte de las personas penadas por delitos que atenten contra la indemnidad y libertad sexuales de personas menores de dieciséis años.

Mención especial es el hecho de que se extiende el tiempo de prescripción de los delitos más graves cometidos contra las personas menores de edad, modificando el día de comienzo de cómputo del plazo: el plazo de prescripción se contará a partir de que la víctima haya cumplido los treinta años de edad y se configura como obligatoria la imposición de la pena de privación de la patria potestad a los penados por homicidio o por asesinato en dos situaciones: cuando el autor y la víctima tuvieran en común un hijo o una hija y cuando la víctima fuera hijo o hija del autor. 
Se introduce como posible sujeto activo en el tipo penal de sustracción de personas menores de edad el progenitor que únicamente tenga en su compañía a la persona menor de edad en un régimen de estancias y se crean nuevos tipos delictivos para evitar la impunidad de conductas realizadas a través de medios tecnológicos y de la comunicación, que producen graves riesgos para la vida y la integridad de las personas menores edad, así como una gran alarma social, como las que promuevan el suicidio, la autolesión o los trastornos alimenticios entre personas menores de edad.

Se reconoce el derecho a la asistencia jurídica gratuita de las personas menores de edad y de las personas con discapacidad necesitadas de especial protección víctimas de delitos violentos graves, con independencia de la situación económica de la víctima y se recoge un completo listado de indicadores de riesgo para la valoración de esta situación a las Entidades Públicas de protección de menores.

Se regulan las condiciones y el procedimiento aplicable a las solicitudes de acogimiento transfronterizo de menores procedentes de un Estado miembro de la Unión Europea o de un Estado parte del Convenio de la Haya de 1996 y se conceden nuevos derechos de las víctimas de delitos de violencia de género cuando el autor de los hechos sea una persona menor de dieciocho años en línea con Estatuto de la víctima del delito.

Por lo que a nosotros más nos interesa ahora se modifica la Ley 15/2015, de 2 de julio, de la Jurisdicción Voluntaria para asegurar el derecho de los niños, niñas y adolescentes a ser escuchados en los expedientes de su interés, salvaguardando su derecho a la defensa, expresarse con libertad y garantizando su intimidad, tras lo que, en fin, se encomienda al Gobierno la elaboración de dos proyectos de ley con el fin de establecer la especialización de la jurisdicción penal y civil, así como del Ministerio Fiscal.

\section{REFERENCIAS}

Naciones Unidas. Derechos Humanos. Oficina del Alto Comisionado (1990). Convención sobre los Derechos del Niño. https://www.ohchr.org/ $\mathrm{sp} /$ professionalinterest/pages/crc.aspx

Jefatura de estado (2021). Ley Orgánica 8/2021, de 4 de junio, de protección integral a la infancia y la adolescencia frente a la violencia. "BOE" núm. 134, de 5 de junio de 2021, páginas 68657 a 68730 (74 págs.). https://www.boe.es/buscar/act.php?id=BOE-A-2021-9347 
Jefatura de Estado (2000). Ley 1/2000, de 7 de enero, de Enjuiciamiento Civil. Publicado en "BOE" núm. 7, de 08/01/2000. https://www.boe.es/ buscar /act.php?id=BOE-A-2000-323\&p=20190415\&tn=1

Jefatura de Estado (2015). Ley Orgánica 8/2015, de 22 de julio, de modificación del sistema de protección a la infancia y a la adolescencia. Publicado en “BOE" núm. 175, de 23 dejulio de2015, páginas 61871 a 61889 (19 págs.) https://www.boe.es/diario boe/txt.php?id=BOE-A-2015-8222

Jefatura de Estado (2004). Ley Orgánica 1/2004, de 28 de diciembre, de Medidas de Protección Integral contra la Violencia de Género. Publicado en "BOE" núm. 313, de 29/12/2004. https:/ / www.boe.es / buscar/act.php?id=BOE-A-2004-21760

Ministerio de Gracia y Justicia Español (1889). Real Decreto de 24 de julio de 1889 - Código Civil español. Publicado en Gaceta de Madrid. núm. 206, de 25/07/1889. https://www.boe.es/buscar/pdf/1889/BOEA-1889-4763-consolidado.pdf

Fecha de recepción : 2 de junio de 2021

Fecha de aceptación : 31 de octubre de 2021 